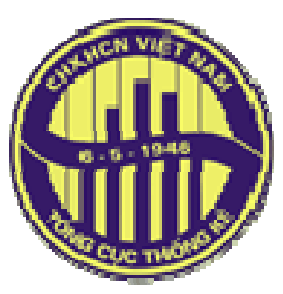

\title{
Vietnam labour market and informal economy in a time of crisis and recovery 2007-2009
}

\author{
Main findings of the Labour Force Surveys (LFS) \\ Policy Brief \\ GSO-ISS/IRD-DIAL project
}

December 2010

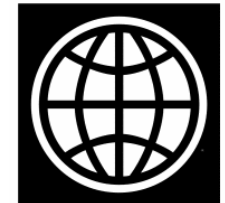

THE WORLD BANK

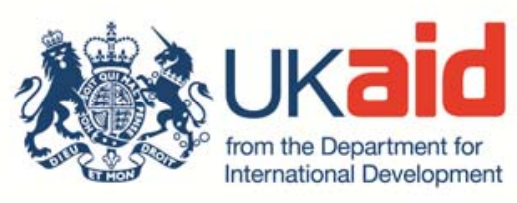

International Development 


\section{Vietnam labour market and informal economy in a time of crisis and recovery 2007-2009 \\ Main findings of the Labour Force Surveys (LFS) ${ }^{1}$}

In 2007 the General Statistics Office (GSO) launched a joint research program with the French Institute of Research for Development (IRD) to measure and analyse the informal sector in Vietnam. Two kinds of surveys were conducted in 2007: a national labour force survey (LFS) which, in a first for Vietnam classified labour by institutional sector thereby separating out the informal sector; and two specific surveys in Hanoi and Ho Chi Minh City (HCMC) which were grafted onto the LFS2007 to find out more about the characteristics of household businesses (HB) in general and especially the informal sector (HB\&IS2007). These surveys have been extensively analyzed and the full results edited in a book (Cling et al., 2010a). Two years later this successful experience has been re-conducted with the additional objectives to consolidate the methodology and to assess the impact of the global crisis on the labour market in general and the informal economy in particular. In late 2009 the LFS was implemented again nationwide, and included the information on the informal sector on behalf of the project, while the HB\&IS survey was replicated in the two provinces (Hanoi and HCMC) with two sub-samples: one panel sample of the HBs already surveyed in 2007, and one new sample of HBs drawn from the LFS2009.

This brief presents the main findings (both methodological and analytical) of these two rounds of LFS as regards the labour market and the informal economy in Vietnam. In the context of the global crisis, it looks at the dynamics of the main labour market indicators with a special focus on informal sector and informal employment between 2007 and $2009 .^{2}$ For the first time ever in Vietnam, it is possible measure precisely the evolution of the informal economy and to check for the robustness of the estimates provided. In the conclusion we outline some of the implications of the findings in terms of survey design and economic and social policies. This brief complements two companion papers, one on the impact of the crisis on the informal sector in Hanoi and HCMC, the other on the dynamic of household businesses in these two cities, both based on the HB\&IS2007 \& 2009 surveys (Cling et al., 2010b; Demenet et al., 2010).

As other Asian countries, Vietnam has been affected by the international crisis and economic growth has slowed down. Whereas, the average annual growth rate has reached $8.5 \%$ in $2004-$ 2007 , it reduced to $6.5 \%$ in 2008 and $5.3 \%$ in 2009. Although the impact of the global crisis was large, it might not be as large as in other countries in the region. With China, Vietnam has been one of the few Asian countries not in recession in 2009. Three main elements might explain why Vietnam is less affected by the crisis than the others: Vietnam was hit by a financial crisis in early 2008, before the international crisis started, and had to react by taking corrective measures; its economy is still predominantly rural (agriculture represents $50 \%$ of employment) and therefore less affected by the global crisis than more developed Asian economies; lastly, figures based on export turnover indicate that Vietnamese exports are still growing in 2009 in contrast to those of other Asian countries, which is due to a combination of price (especially increase of rice prices) and competitiveness effects.

\footnotetext{
${ }^{1}$ This policy brief has been written by Nguyễn Hữu Chí and Nguyễn Thị Thu Huyền (GSO), and Mireille Razafindrakoto and François Roubaud (IRD-DIAL).

${ }^{2}$ The figures in this brief may slightly differ from the official ones (GSO, 2008 \& 2010) due to difference in conventions adopted in some indicators. We would to thank the Population and Labour Department (GSO), in particular Đồng Bá Hướng, Hoàng Xuyên and Phan Thị Minh Hiền, and Margarita Guerrero (UNDP) for their support in the process of revising the LFS2009 questionnaire.
} 
Many studies have tried to assess the impact of the global crisis on the Vietnamese economy. Some reports focus more on the main changes of the macro-economic indicators (GDP, export, production by sector, FDI, State budget) in order to have a quick overview of the situation (Le Dang Doanh, 2009; World Bank, 2009 and Riedel, 2009). Fewer papers focused on the households living conditions and the labor market. However, all of them acknowledged the impact of the crisis on household income might be quite harmful as potentially some workers will shift to lower paid jobs in the informal sector or return to agricultural activities. Unfortunately, due to the lack of reliable and relevant data, we know almost nothing on the share of the population who has experienced a job-loss or a sharp income drop. The great majority of the existing reports at the micro-level rely on qualitative analysis of some specific sub-sectors or categories of the population (Turk and Mason, 2010). Ngoc Q. Pham (2009) reports job losses in some firms (mainly foreign-invested companies) in Hanoi and HCMC, less jobs created, reduced working time, and/or reduced income. The VASS reports (VASS, 2009; Dinh Thi Thu Phuong, 2009; Nguyen Ngoc Anh, 2009; Nguyen Tam Giang, 2009) are based on case studies and focuses on migrant workers in "cho lao dong" (daily recruitment market places), in the craft villages and in industrial parks. It also concludes that they faced reduced work opportunities, job losses or reduced income. Relying on a self-assessment information from farmers in 4 provinces, a report by a research group of IPSARD (2009) argued that more than $20 \%$ of migrant workers from rural areas lost their job and returned home with poor communes being more adversely affected than non-poor communes. Among them, only $11 \%$ found new jobs.

On the quantitative front, only two studies launched by UNDP (Warren-Rodriguez, 2009; Nguyen Viet Cuong et al., 2009) intend to measure the global impact of the crisis on the labour market. Using a similar methodology, based on employment elasticities to growth, both studies converge in forecasting a significant slowdown in the job creation and consequently strong increase of the unemployment rate, (from $4.6 \%$ to between $6.7 \%$ and $7.6 \%$, for the urban rate). At odds with all these studies, Cling et al. (2010c) suggest that unemployment will not be the main labour market response to the crisis, the informal sector being a key component to clear labour demand and supply. Now that survey data have been made available, it is possible to evaluate the accuracy of these different views based on empirical evidence.

\section{A slight increase of activity rates, concentrated among young and old workers}

Adverse conditions on the labour market may have two opposite effects on the activity rate. On the one hand, it may exert pressure on some segments of the inactive population to enter the labour market. On the other hand, the groups with the weakest attachment to the labour market may withdraw as 'discouraged workers' (a phenomenon known as the activity rate's flexion). The empirical evidence suggests that the former effect largely dominate the latter.

A slight increase of activity rates, in particular in urban areas. The activity rate has increased slightly, from $74.5 \%$ to $75.8 \%$. At the same time, the share of discouraged workers (defined as the inactive who didn't look for a job because they believe no job is available for their skills or because they don't know how to look for a job) among the inactive population remained at its structural very low level of $1 \%$. To investigate further this issue and be sure that it is not just due to a composition effect, we disaggregate the labour force by category. First, the global increase is mainly due to urban areas ( +3.5 percentage points), where the impact of the crisis is the most sensitive. In rural areas, the limited upwards trend ( +0.7 points) is only due to males, while the activity rate remained unchanged for females $(74.7 \%)$. 
Table 1: Activity rates by area and gender, 2007 \& 2009

\begin{tabular}{lcccccc}
\hline & \multicolumn{3}{c}{$\mathbf{2 0 0 7}$} & \multicolumn{3}{c}{$\mathbf{2 0 0 9}$} \\
\cline { 2 - 7 } Male & Urban & Rural & Total & Urban & Rural & Total \\
\cline { 2 - 7 } Female & 72.1 & 81.3 & 78.8 & 75.3 & 82.6 & 80.4 \\
\hline Total & 60.8 & 74.7 & 70.7 & 64.2 & 74.7 & 71.5 \\
\hline
\end{tabular}

Sources: LFS, 2007 \& 2009, GSO. Total: 15 years old or more; authors' calculations.

Changes occurred mainly among young and old workers. Second, looking more in detail at the evolution of the activity rate by age group, the main changes are concentrated among young and old people. For instance, for the youngest (15-19 years old), the activity rate is +4.8 points higher in 2009 compared to 2007 . The gap still remained at +2 pts between age 20 to 29, and then becomes insignificant for older groups. It is only at the other tail of the age distribution the adverse conditions seems to have pushed up the participation to the labour market: from 55 years old onwards, the activity rates are +2 points to 3 points higher in 2009 than in 2007 . Clearly, a first effect of the international crisis is to have pushed the "secondary" manpower of the household (youngest, oldest, etc.) to integrate into the labour market, to counteract the worsening labour conditions of the usually working population. This trend may have negative impacts, notably on schooling rates which we are unfortunately unable to assess as the question on education was unavailable in the LFS2009.

Figure 1: Activity rate by age groups, 2007 \& 2009

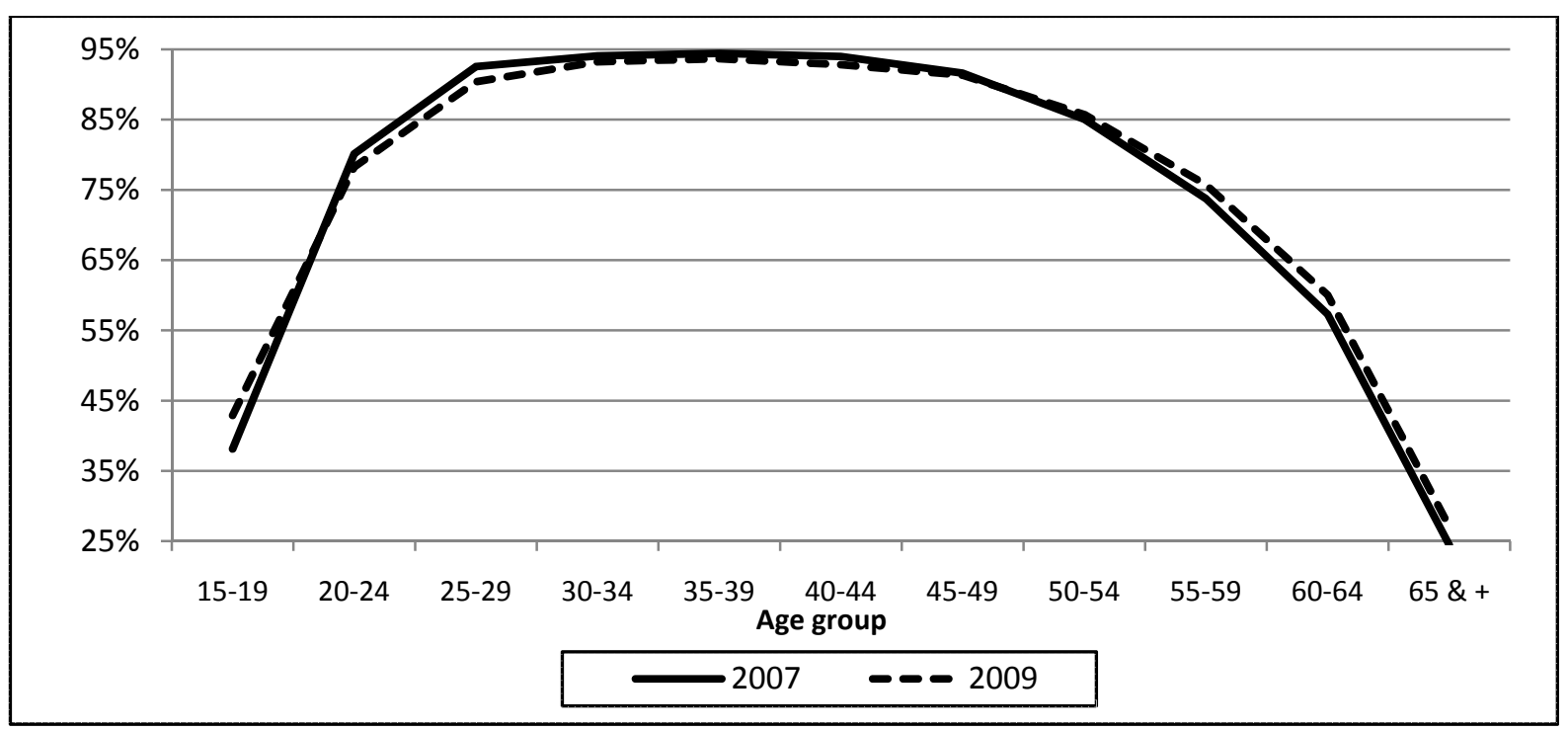

Sources: LFS, 2007 \& 2009, GSO. Total: 15 years old or more; authors' calculations.

\section{A structurally low unemployment rate, with significant downward trend for young workers}

The increase in the unemployment rate is the most widely expected effect of the crisis on the labour market. As quoted above, previous studies in Vietnam have forecast a significant upsurge in unemployment. At the international level, the first available data confirmed this expectation (ILO \& IMF, 2010). In this respect, three main features are important: a) a significant increase in global unemployment rates; b) a particular impact on youth 
unemployment; and c) a rise of long term unemployment. The data in Vietnam shows exactly the inverse pattern.

No increase in global unemployment rates. Not only there was no burst in unemployment, but it actually decreased: the unemployment rate went down from its structurally low level of $2.0 \%$ in 2007 to $1.7 \%$ in 2009 (a too small change to be statistically significant). In less developed countries like Vietnam, the urban unemployment is more meaningful than the rural one. However, the unemployment rate is on the decline everywhere, and especially in urban areas (from $3.6 \%$ in 2007 to $2.8 \%$ in 2009). Female workers present a higher reduction in the unemployment rate (-0.7 point) than males (-0.2 points), especially in urban areas.

Table 2: Unemployment rates by area and gender, 2007 \& 2009

\begin{tabular}{lcccccc}
\hline & \multicolumn{4}{c}{$\mathbf{2 0 0 7}$} & \multicolumn{3}{c}{$\mathbf{2 0 0 9}$} \\
\cline { 2 - 7 } Male & Urban & Rural & Total & Urban & Rural & Total \\
\cline { 2 - 7 } Female & 3.5 & 1.5 & 2.0 & 3.2 & 1.3 & 1.8 \\
\hline Total & 3.6 & 1.3 & 1.9 & 2.5 & 1.1 & 1.2 \\
\hline
\end{tabular}

Sources: LFS, 2007 \& 2009, GSO. Total: 15 years old or more; authors' calculations.

But unemployment rate is not an adequate indicator to monitor the labour market. This evolution of unemployment rate with the business cycle does not come at a surprise. It is nowadays widely acknowledged that open unemployment is not the best indicator of market clearing in developing countries. In such countries where wage relations cover a low percentage of the labour force and where unemployment risk is not covered by social institutions, the shortage of labour demand passes through other mechanisms than unemployment (Cling et al., 2010c).

Figure 2: Unemployment and GDP Growth in Vietnam, 1996-2009

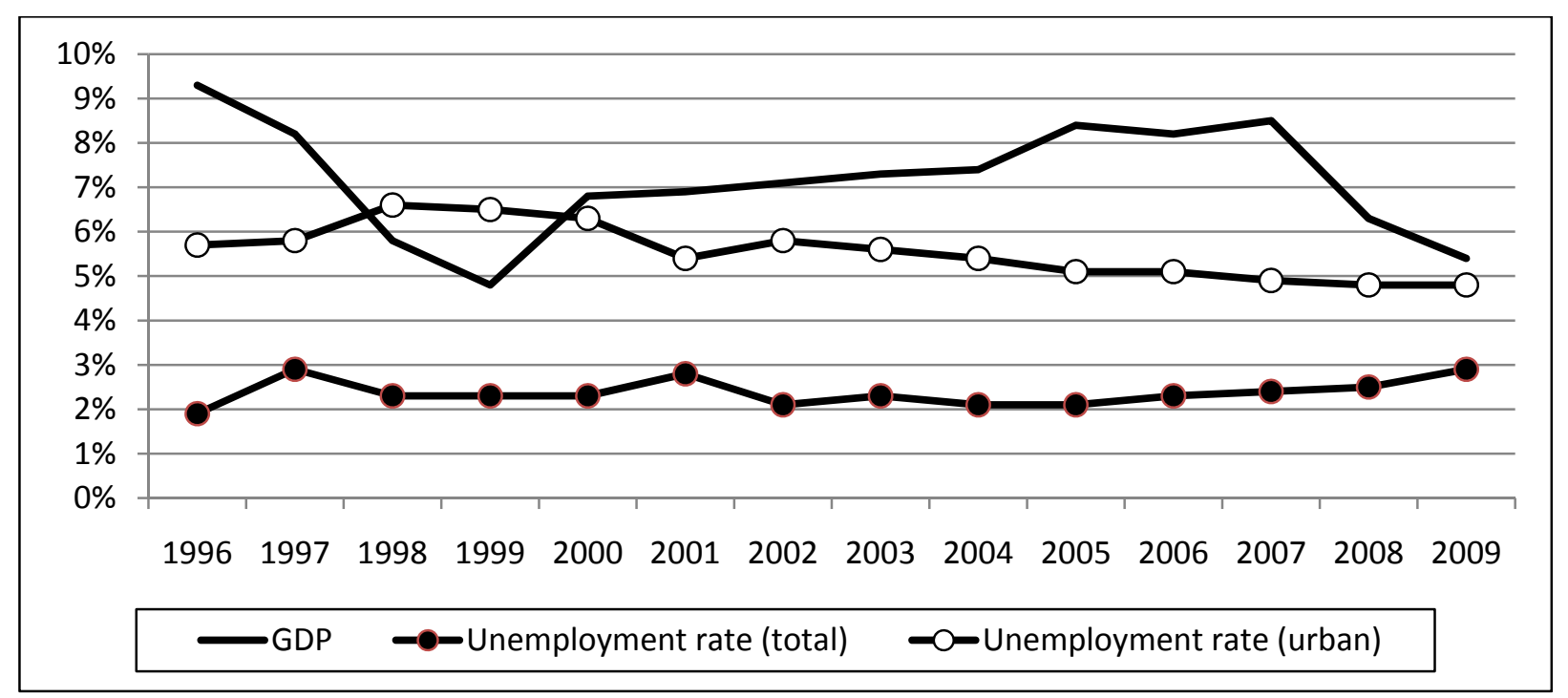

Sources: MoLISA \& GSO, 1996-2009; authors' calculations.

Note: the unemployment rate is the official one. In 2007 \& 2009, it slightly differs from our computation due to differences in conventions (the GSO restricts the unemployed to males aged $[15,59]$ and females aged $[15,54]$ ). 
This is obviously the case in Vietnam. As shown in Figure 2, the unemployment rate is rather inelastic to the variations of GDP growth. The unemployment curve is quite flat and low. At its highest, unemployment picked up at 2.9\% (1997), while it went down to $1.9 \%$ at its lowest (1996), over the last decade. Over all the following years (1998-2007), the unemployment rate fluctuated in a very narrow range, between $2.8 \%$ (2001) and $2.1 \%$ (2003 and 2004), levels which are statistically undistinguishable. In urban areas, the unemployment rate is higher and more elastic to growth. Nevertheless, during the worst period of the Asian crisis, the GDP growth decreased by 5 percentage points (from $9.3 \%$ in 1996 to $4.8 \%$ in 1999), but the urban unemployment rate rose by less than 1 percentage point (from $5.7 \%$ to $6.5 \%$ ). If we consider the Asian crisis as a benchmark, the deceleration of growth being of the same order of magnitude than between 2007 and 2009, the rise in unemployment should be very limited.

A significant decrease of unemployment rate for the young generation. Furthermore, contrary to what has been observed in industrialized countries, the major (significant) reduction in unemployment is focused on (urban) youth. In 2007, 14.6\% of the urbanites aged 15-19 years old were unemployed. They were only $8.1 \%$ two years later, corresponding to a 6.5 points decrease. For the group aged 20-24 the decline is -2.2 points, while changes for the older groups are unnoticeable. We observe the same pattern in rural areas, but to a lesser extent. If some difficulties in finding a job still remain for the younger generation (insertion unemployment), the crisis seems to have facilitated the access to jobs and narrowed the unemployment gap between generations.

Figure 3: Unemployment rate by age groups and area, 2007 \& 2009

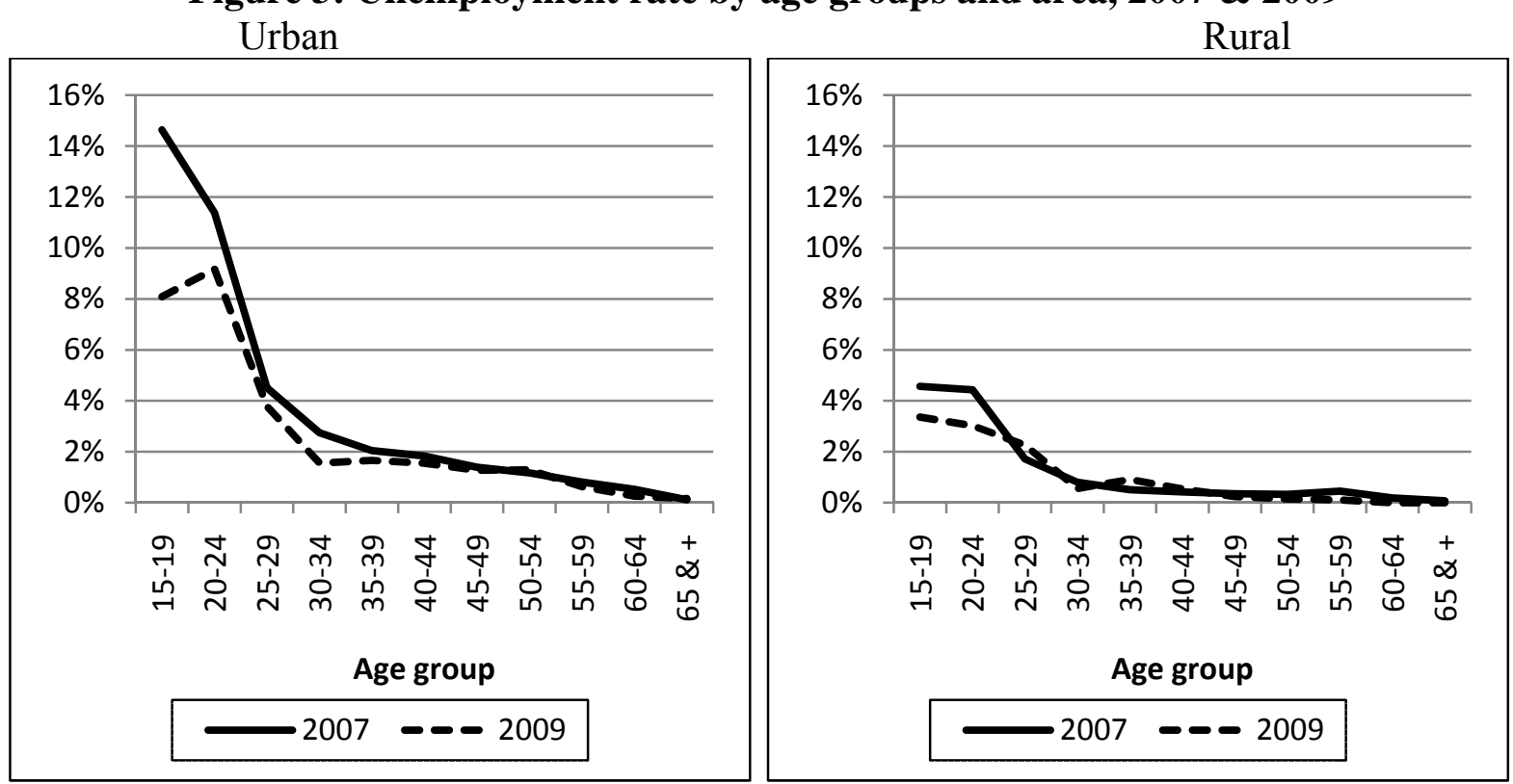

Sources: LFS, 2007 \& 2009, GSO. Total: 15 years old or more; authors' calculations.

A decrease of long term unemployment. Finally, in contrary to what occurred in industrialized countries, the average duration of unemployment has been reduced more than two folds (15 months in 2007 vs. 7 months in 2009), inducing a corresponding decrease in the long term unemployment (more than one year), from $30 \%$ of unemployment to $16 \%$ two years later. 
Table 3: Unemployment rates by area and gender, 2007 \& 2009

\begin{tabular}{|c|c|c|c|c|}
\hline & \multicolumn{2}{|c|}{$\begin{array}{l}\text { Average duration of unemployment } \\
\text { (month) }\end{array}$} & \multicolumn{2}{|c|}{$\begin{array}{c}\text { Long term unemployment } \\
(\%)\end{array}$} \\
\hline & 2007 & 2009 & 2007 & 2009 \\
\hline Urban & 15.8 & 8.1 & 31.3 & 18.1 \\
\hline Rural & 13.9 & 5.7 & 29.1 & 14.5 \\
\hline Total & 14.8 & 6.8 & 30.1 & 16.2 \\
\hline
\end{tabular}

Sources: LFS, 2007 \& 2009, GSO. Total: 15 years old or more; authors' calculations.

Taken together, the increase in the activity rate and the decrease in the unemployment rate show that more people have been sent by the households to the labour market to cope with the crisis, and they succeeded in getting a job. Thus, the adjustment between supply and demand of labour should have been translated to the jobs' quality, as stressed by a recent study for a wide range of middle income countries (Khanna et al., 2010). We will explore this point in the following sections. What is certain, however, is that the unemployment rate is not a good indicator of labour market clearing in Vietnam (and probably in most LDCs).

\section{A resilient job's distribution by institutional sector}

Assessing the impact of the crisis on the labour markets, the ILO \& IMF (2010) claim that in LICs, the informal sector jobs should be on the rise. In the case of Vietnam, this shift has been also quoted by us (Cling et al., 2010c). In 2009 (previous to the availability of the LFS2009 data), and based on a set of hypotheses (in particular the unemployment elasticity to growth), we forecasted an increase of employment in the informal sector, which corresponds approximately to $+6.5 \%$ jobs in 2009 compared with 2008 .

No significant changes in the structure of employment. The results from the LFS2009 confirm that the informal sector jobs grew between 2007 and 2009 (500,000 new jobs, which corresponds to a $+4.9 \%$ increase). The distribution by institutional sectors shows that the informal sector slightly increased its share of total employment, from $23.4 \%$ to $23.7 \%$. Surprisingly, the main feature in Table 4 is that the general structure did not change significantly with the crisis. Agricultural jobs continue their declining pattern ( -2.3 percentage points), in line with previous trends, showing that Vietnam did not experienced any massive return migration to rural areas and agriculture. Public jobs also reduced their share $(-0.8$ points), also consistent with the previous trends.

Table 4: Employment by institutional sector and area, 2007 \& 2009

\begin{tabular}{lcccccc}
\hline & \multicolumn{3}{c}{$\mathbf{2 0 0 7}$} & \multicolumn{3}{c}{$\mathbf{2 0 0 9}$} \\
\cline { 2 - 7 } Public & Urban & Rural & Total & Urban & Rural & Total \\
\cline { 2 - 7 } Foreign Enterprise & $23.8 \%$ & $6.1 \%$ & $10.5 \%$ & $20.2 \%$ & $5.7 \%$ & $9.7 \%$ \\
Domestic Enterprise & $3.4 \%$ & $1.5 \%$ & $2.0 \%$ & $3.8 \%$ & $2.5 \%$ & $2.9 \%$ \\
Formal HB & $11.6 \%$ & $3.8 \%$ & $5.7 \%$ & $14.5 \%$ & $5.1 \%$ & $7.7 \%$ \\
Informal sector & $16.9 \%$ & $4.7 \%$ & $7.7 \%$ & $15.1 \%$ & $5.0 \%$ & $7.8 \%$ \\
Agriculture & $31.5 \%$ & $20.8 \%$ & $23.4 \%$ & $31.6 \%$ & $20.7 \%$ & $23.7 \%$ \\
\hline Total & $11.1 \%$ & $63.0 \%$ & $50.4 \%$ & $14.7 \%$ & $60.9 \%$ & $48.1 \%$ \\
\hline
\end{tabular}

Sources: LFS, 2007 \& 2009, GSO. Total: Occupied population; authors' calculation. 
The informal sector and, more surprisingly, the private formal sector benefited from the shrinking share of the two above mentioned institutional sectors. The FDI sector experienced the highest job's growth with a huge $+52 \%$ (mainly in rural areas), even if it still accounts for less than $3 \%$ of the labour force. Domestic enterprises follow, with 1 million additional jobs $(+40 \%$ and a 2 points increase in the distribution), and lastly the formal household business jobs, with 100,000 new jobs in 2 years.

An increase of the rate of wage workers. Another way to cross check previous results is to investigate the dynamics of employment along job status. ${ }^{3}$ One may expect that the crisis has impacted job vulnerability, by reducing the creation of wage jobs, or at least by lowering its growth rate. Furthermore, women may have held the burden of this increased precariousness. In fact, in two years, the wage workers rate gained +3.6 percentage points, from $30 \%$ in 2007 to $33.6 \%$ in 2009 , which corresponds to a net creation of 2.15 million additional wage jobs (Table 5). The increase is due to the combined effects of a global shift towards sectors where wage relations are more frequent (formal sectors) and an increase in the wage workers rate (non-farm household businesses and agriculture).

Table 5: Wage workers rates by institutional sector, 2007 \& 2009

\begin{tabular}{lcccccc}
\hline & \multicolumn{2}{c}{ Female } & \multicolumn{2}{c}{ Male } & \multicolumn{2}{c}{ Total } \\
\cline { 2 - 7 } Public & $\mathbf{2 0 0 7}$ & $\mathbf{2 0 0 9}$ & $\mathbf{2 0 0 7}$ & $\mathbf{2 0 0 9}$ & $\mathbf{2 0 0 7}$ & $\mathbf{2 0 0 9}$ \\
\cline { 2 - 7 } Foreign Enterprise & 99.5 & 99.7 & 99.2 & 99.7 & 99.3 & 99.7 \\
Domestic Enterprise & 99.2 & 99.9 & 99.7 & 100 & 99.3 & 99.9 \\
Formal HB & 93.1 & 96.1 & 92.5 & 92.1 & 92.5 & 93.6 \\
Informal sector & 28.0 & 30.1 & 41.2 & 41.8 & 35.0 & 36.4 \\
Agriculture & 12.5 & 12.0 & 35.0 & 40.0 & 23.9 & 26.7 \\
\hline Total & 5.4 & 7.3 & 9.6 & 11.8 & 7.5 & 9.6 \\
\hline Sourcenyyyyyyyyyyyyy
\end{tabular}

Sources: LFS, 2007 \& 2009, GSO. Total: Occupied population; authors' calculation.

Note: Cooperative members have been aggregated with wage workers. This does not make any change as they account for $0.15 \%$ of the labour force in 2007 and $0.12 \%$ in 2009 .

Additionally, both men and women have benefited from this process. Again, if women suffer from a lower wage workers rate $(27.7 \%$ vs. $39.1 \%$ in 2009$)$, this is mainly due to their higher concentration in sectors where wage relations are limited (NFHB and agriculture), and to a lower wage workers rate in these sectors, while no significant differences can be observed in the formal sector. In this respect, the case of the informal sector is atypical. While the wage workers rate is $40 \%$ (in 2009) for male and has increased (compared to $35 \%$ in 2007), it is only $12 \%$ for their female counterparts and the rate remain stable.

\section{A slight improvement of labour conditions}

We now turn to a more in depth analysis of job vulnerability along job status in two directions. First, we disaggregate non wage workers into different categories: employers, own account workers and contributing family workers (Figure 4). At the global level, the share of employers grew slightly, from $3.2 \%$ to $4.8 \%$, which is consistent with the improvement in job status quoted above. However and more strikingly, the own account share decreased sharply (from $53.4 \%$ to $44.7 \%$ ), in part to the benefit of contributing family workers, whose share

\footnotetext{
${ }^{3}$ The different job status are: employers, own account workers (heads of HB which does not employ any wage workers), unpaid family workers, wage workers (workers who receive a salary), apprentice.
} 
gained +3.5 points ( $13.5 \%$ and $17 \%$ respectively). These figures may be credible (in the sense of an increased vulnerability due to the crisis), but a closer look by gender and areas casts doubts on these changes. The shift between own account workers and contributing family workers is focused on rural areas and women, while no big changes are observed for men, and no changes at all in urban areas. To give an order of magnitude, the share of female own workers decreased by -11.5 percentage points, a drop largely compensated by the share of family workers (+7.9 points). The respective figures are -10.2 and +4.8 points in rural areas (15.4 and +10.6 points for female in rural areas). Our own interpretation is that these enormous changes are primarily due to measurement errors, given the blurred boundaries between the two categories, more than to real evolution in the job status which is a longstanding acknowledged problem in Vietnamese surveys (Roubaud et al., 2008; ILO, 2010).

Figure 4: Job status by gender and area, 2007 \& 2009

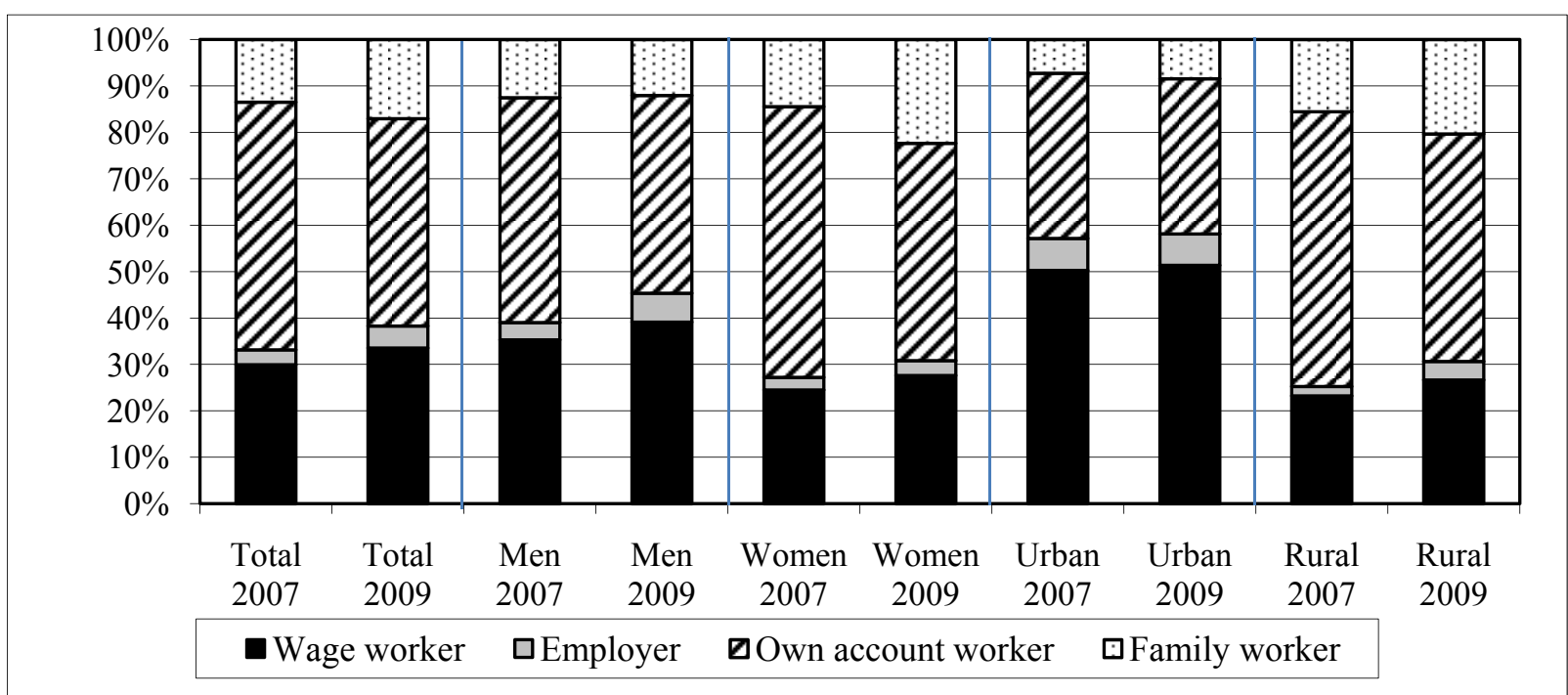

Sources: LFS, 2007 \& 2009, GSO. Total: Occupied population; authors' calculation.

Note: as in table 5, cooperative members have been aggregated with wage workers. On-the-job trainees have been summed up with unpaid family workers. This does not make any change as the formers account for $0.16 \%$ of the labour force in 2007 and $0.18 \%$ in 2009.

Second, if we look at wage workers, the quality of wage relations highly depends on the nature of contracts and the mode of remuneration. The crisis may have an effect on both by increasing precariousness (short time contracts or no contract at all; variable earnings depending on productivity). Obviously, this is not the case. Even if we are far from the stable and regulated situation of wage relations observed in developed countries (long term contracts and fixed wage), wage workers are in a (slightly) better position in 2009 compared to 2007. Indefinite term contracts are a bit less common $(29.4 \%$ vs. $31.8 \%)$, but at the same time wage workers with no contract are also less numerous (11.1\% vs. $13.6 \%$; see Table 5$)$. At the same time, fixed remuneration gained 3 percentage points (from $50.4 \%$ to $53.4 \%$ ), at the expense of per day/hour, per piece or remuneration in kind. It should be stressed that contrary to the common belief, female wage workers do have more secure employment arrangement than men. For instance, $34.2 \%$ get permanent written contracts and $60.3 \%$ are regularly paid employees, while the respective numbers are $26.2 \%$ and $48.8 \%$ for men (2009 figures). This advantage for women can be explained by their relative overrepresentation in institutional sectors with more formalized labour relations (FDI, etc.). All in all, the contractual relations of wage workers have slightly improved over the two years, and have been equally shared by men and women. 
Table 6: Wage worker's contracts and mode of payment, 2007 \& 2009

\begin{tabular}{|c|c|c|c|c|c|}
\hline & 2007 & 2009 & & 2007 & 2009 \\
\hline Indefinite contract & 31.8 & 29.4 & Fixed wage & 50.4 & 53.4 \\
\hline Fixed term contract & 24.7 & 25.8 & Per day/hour & 29.4 & 28.0 \\
\hline Verbal agreement & 29.8 & 33.6 & Per piece & 17.9 & 17.5 \\
\hline No contract & 13.6 & 11.1 & Other & 2.4 & 1.0 \\
\hline Total & 100.0 & 100.0 & Total & 100.0 & 100.0 \\
\hline
\end{tabular}

Sources: LFS, 2007 \& 2009, GSO. Total: wage workers; authors' calculation.

Note: other types of payment include on commission, interest, in kind and unpaid.

To finalise this section on job status and get an overall assessment for all kind of workers (whether salaried or not), let's consider the dynamics of informal employment. Informal employment is a comprehensive indicator of job insecurity. The ILO has developed the concept of informal employment (ILO, 2003) in an extension of the concept of informality. The rationale of such an extension is to take into account the new precarious forms of jobs that have developed worldwide as a result of globalisation (internationalisation of firms, labour market deregulation and flexibilization). In line with international recommendations, the GSO has adopted the following definition: informal employment is defined as all employed workers not covered by the social insurance system, irrespective of the institutional sector in which they are employed (see Cling et al., 2010a).

A huge rate of informal employment. At the national level, informal employment represents $80.5 \%$ of total jobs in 2009 (Table 7), which means that only 9 million workers are covered by the social insurance scheme (mandatory or voluntary; VASS, 2010). This figure corresponds to a small drop compared to 2007 (81.9\%). Furthermore, such a fall should be considered as a conservative estimate, as all contributing family workers are classified as informal employment (by definition) and this group grew by +3.5 points between 2007 and 2009 , a change we consider unrealistic (see above). The rate of informal employment varies a great deal among sectors, obviously picking up in the informal sector and agriculture. But formal sectors are not spared. The reduction is the most noticeable for foreign and domestic enterprises ( -4.3 and -4.9 percentage points respectively).

Table 7: Informal employment in the main job by institutional sector, 2007 \& 2009

\begin{tabular}{|c|c|c|c|c|c|c|c|c|}
\hline & \multirow{2}{*}{$\begin{array}{r}\text { Number } \\
(1,000) \\
\end{array}$} & \multirow{2}{*}{$\begin{array}{c}\text { Structure } \\
(\%) \\
\end{array}$} & \multicolumn{6}{|c|}{ Enterprise's institutional sector (\%) } \\
\hline & & & Public sector & $\begin{array}{c}\text { Foreign } \\
\text { enterprise }\end{array}$ & $\begin{array}{l}\text { Domestic } \\
\text { enterprise }\end{array}$ & Formal HH & $\begin{array}{c}\text { Informal } \\
\text { sector }\end{array}$ & $\begin{array}{l}\text { Agricul- } \\
\text { ture }\end{array}$ \\
\hline 2007 & 37,705 & 81.9 & 12.3 & 17.2 & 52.9 & 48.0 & 100 & 99.0 \\
\hline 2009 & 38,288 & 80.5 & 12.6 & 12.9 & 48.0 & 51.6 & 100 & 98.6 \\
\hline
\end{tabular}

Source: LFS2007, GSO; authors' calculations.

Note: Total employment is not exactly the sum of employment in all sectors, because $0.3 \%$ of jobs cannot be classed in a given institutional sector.

Urban areas are less affected by informal employment than rural ones (60.9\% vs. 88.0\%), even if the former is the only one where informal employment increased over the two years (by $58.0 \%$ in 2007). In terms of gender balance, women are no more informally employed than men. Again, and contrary to the expectations, the crisis didn't hit women working in the informal economy the most (Horn, 2010). Finally, all indicators are consistent in suggesting a smooth improvement of labour relations between 2007 and 2009. 


\section{An impressive growth of labour earnings}

The crisis may have impacted the earnings, through wage cuts or wage moderation in the formal sector, and through quantity or price adjustment in the informal sector. For the latter, various mechanisms may be at stake. On the labour supply side, the additional employment in the informal sector should entail increased competition between informal production units, and exert pressures on the average turnover and income. On the demand side, there could be a shift of household consumption from formal to informal products (due to income elasticity effects), but as the informal sector already provides the major part of the household consumption, this effect should be limited. In fact, the informal sector may suffer from the contraction of demand. In general among the non agricultural sectors, the informal sector income is the most flexible to downward pressure and should logically be more affected than the wages in the formal sectors.

Between 2007 and 2009, the monthly earning (in the main job) in nominal terms increased from 1,060 million VND to 1,600 million VND, corresponding to $+52 \%$ growth over the two years. This result is quite robust to alternative first order income measures, as the median income growth is very similar $(+50.5 \%)$. The income structure is classically at its highest for the formal sectors (both public and private), while the informal sector occupies an intermediary position between the formal sector and agriculture. But, the informal sector did not seem to hold the burden of the crisis, as there is no diverging pattern between formal and informal sectors. The informal sector registered the second highest increase, with $+57.1 \%$, just after domestic enterprises $(+76.8 \%)$ and ahead of public sector, foreign enterprises and formal household businesses $(+56.6 \%,+53.9 \%$ and $+44.2 \%$, respectively). The only exception is agriculture jobs, which obtained the lowest growth rate with $+38.6 \%$. Taking into account that these jobs are the less paid, such a dynamic have direct consequences on earning inequalities.

Obviously, the nominal income growth presented in the table 8 should be adjusted for inflation over the period considered, notably in 2008. At the national level, the CPI rose by $+30.9 \%$ between the two surveys. To compute the real income growth, we elaborated a price deflator, taking into account spatial differences in the price level, as well as time changes. The geographical deflators drawn from the VHLSS 2006 (the nearest survey with the required information) have been applied to the LFS2007. They distinguish 16 price levels ( 8 regions by 2 areas: urban and rural). Then we applied a time deflator to the LFS2009 data, resulting from the aggregation of the provincial CPI at the regional level (which means that within each province, the same inflation rate has been computed for rural and urban areas). Some further adjustments have been made due to the changes of the regional boundaries.

Table 8: Average and median income growth by institutional sector, 2007 \& 2009

\begin{tabular}{lcccccc}
\hline & \multicolumn{3}{c}{ Real average income } & \multicolumn{3}{c}{ Real median income } \\
\cline { 2 - 7 } Public & $\mathbf{2 0 0 7}$ & $\mathbf{2 0 0 9}$ & Change & $\mathbf{2 0 0 7}$ & $\mathbf{2 0 0 9}$ & Change \\
\cline { 2 - 7 } Foreign Enterprise & 1,632 & 1,964 & $20.4 \%$ & 1,477 & 1,763 & $19.4 \%$ \\
Domestic Enterprise & 1,457 & 1,735 & $19.1 \%$ & 1,135 & 1,332 & $17.3 \%$ \\
Formal HB & 1,550 & 2,093 & $35.1 \%$ & 1,217 & 1,523 & $25.2 \%$ \\
Informal sector & 1,645 & 1,805 & $9.7 \%$ & 1,217 & 1,302 & $7.0 \%$ \\
Agriculture & 1,066 & 1,273 & $19.4 \%$ & 923 & 1,063 & $15.3 \%$ \\
\hline Total & 672 & 703 & $4.7 \%$ & 436 & 443 & $1.7 \%$ \\
\hline
\end{tabular}

Sources: LFS, 2007 \& 2009, GSO. Total: Occupied population; authors' calculation. 
Once taken into account the differences in price levels and inflation, the average monthly income of the main job has increased by $+15.3 \%$ in real terms, between 2007 and 2009, a figure in line with the median earning growth $(+13.6 \%)$. Surprisingly, this dynamics is not only positive, but also not substantially lower, on the contrary, than the previous trends. According to the VHLSS data, the annual average real wage growth was $+6.4 \%$ between 2002 and $2004,+6.6 \%$ during the two following years (2004-2006), compared to $+7.4 \%$ between 2007 and 2009.

Figure 5: Income distribution in 2007 and 2009 (Fixed price, 2007)
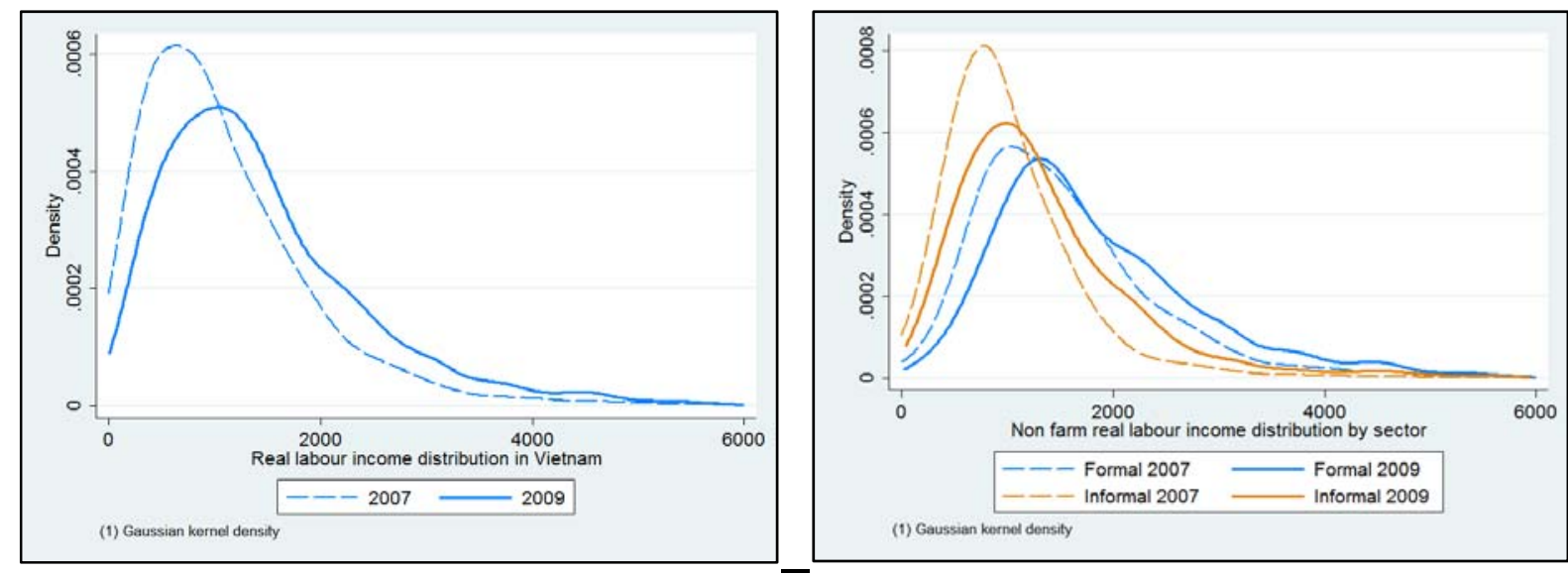

Sources: LFS, 2007 \& 2009, GSO; authors' calculation.

\section{The adjustment mode on the labour market: underemployment and multiactivity}

At this stage, it is very difficult to track any negative impact of the crisis on the labour market, as the indicators are all upwards oriented: notwithstanding the increase in activity rates (especially for young people), the unemployment rate has decreased (especially for young people), the previous shifts out of agriculture and non wage employment pursued at the same pace as in the previous period (notably in favour of formal sectors), contractual relations among wage workers improved and labour earnings have registered an impressive growth. To go further, we will now look at other indicators, like underemployment and multi-activity, which may have been impacted by the GDP growth downturn.

\section{A reduction in the hours worked and a rise of time related underemployment}

While the main structures of the labor market remained globally unaffected, the principal variable of adjustment during the slowdown has been the working hours. The average working time has been reduced by 1.3 hours a week ( 1.7 hours in rural areas and 1.1 hours in urban areas), from 43.9 hours to 42.6 hours between 2007 and 2009. This average does catch the full picture of the increasing heterogeneity in hours worked and the huge adjustment at stake. Part time workers (working less than 35 hours a week) were 13.2\% in 2007. In 2009, they consisted of $26.7 \%$, an increase of more than $100 \%$. 
The time-related underemployment rate, defined as the part of the occupied labour force working less than 35 hours a week and wanting more hours, is on a rise. Unfortunately, it cannot be precisely computed in 2009, as the survey only questions for additional hours wanted not only for the main job, but for all jobs. Nevertheless, the (true) time-related underemployment was $4.9 \%$ in 2007 (2.1\% in urban areas and $5.8 \%$ in rural areas). Two years later, the conservative estimate gives $6.8 \%$ at the national level $(3.6 \%$ and $8.0 \%$ in urban and rural areas). The informal sector and agriculture have suffered the most from these non voluntary cuts in hours.

The LFS2009 provides another way to look at time-related underemployment, by comparing the usual and actual hours worked, and the reasons why the latter is smaller than the former. First, $12.9 \%$ of the labour force are in this case, with a higher proportion in formal $(10.7 \%)$, informal household businesses $(14.6 \%)$ and in agriculture $(16.0 \%)$. The main reasons quoted are more structural than linked to the crisis: $48.2 \%$ stress "bad weather" and $21.8 \%$ "family obligations". But the motivations vary a great deal along institutional sectors. While $61.8 \%$ of agriculture workers mentions "bad weather" and "off-farm", 38.9\% of FHB workers and $26.4 \%$ of IHB ones underline the "lack of clients/orders" in their business. In none of the sectors "job lost", "working hours cut down" or "strike/closed factory" is a significant reason for working less than usual.

But as more workers had to work less, at the other side of the hours ladder, an increasing share of workers had to work more hours to make a living, which is usually considered as another form of "invisible" unemployment: while $5.6 \%$ of the labour force was engaged more than 60 hours a week on the labour market in 2007, they were nearly one out of ten $(9.3 \%)$ two years later. These unexpected figures may be explained by the formidable (and understated) flexibility of the labor market in Vietnam (both in the formal and informal sector), which permits to mitigate the negative impact of the global crisis.

Table 9: Hours worked and underemployment rate by area, 2007 \& 2009

\begin{tabular}{|c|c|c|c|c|c|c|}
\hline & \multicolumn{3}{|c|}{2007} & \multicolumn{3}{|c|}{2009} \\
\hline & Urban & Rural & Total & Urban & Rural & Total \\
\hline Average hours/week & 48.2 & 42.4 & 43.9 & 47.1 & 40.8 & 42.6 \\
\hline Less than 35 hours & 6.0 & 15.6 & 13.2 & 15.4 & 31.0 & 26.7 \\
\hline Underemployment rate* & 2.1 & 5.8 & 4.9 & 3.6 & 8.0 & 6.8 \\
\hline More than 60 hours & 10.4 & 4.0 & 5.6 & 14.2 & 7.4 & 9.3 \\
\hline
\end{tabular}

Sources: LFS, 2007 \& 2009, GSO. Total : Occupied population.

\section{A strong increase in multi-activity rate}

To compensate for this contraction in available hours, more workers had to find additional sources of income by getting a second job. The multi-activity rate gained 7.2 percentage points, from $18.2 \%$ in 2007 to $25.4 \%$ in 2009 . With more than 12 million people taking on additional employment in 2009, 3.6 million additional secondary jobs must have been created in two years which is many more than for the main jobs. The increase is observed in all regions, both for male and female. But even if multiple job's holders are much more frequent in rural areas, the growth in multi-activity is substantially higher than in urban areas (it more than doubles in rural areas). 
Table 10: Multi-activity rate by area and gender, 2007 \& 2009

\begin{tabular}{lcccccc}
\hline & \multicolumn{3}{c}{$\mathbf{2 0 0 7}$} & \multicolumn{2}{c}{$\mathbf{2 0 0 9}$} \\
\cline { 2 - 7 } Male & Urban & Rural & Total & Urban & Rural & Total \\
\cline { 2 - 7 } Female & 4.1 & 21.7 & 17.2 & 8.9 & 29.4 & 23.7 \\
\hline Total & 4.2 & 24.1 & 19.2 & 9.8 & 33.8 & 27.2 \\
\hline
\end{tabular}

Sources: LFS, 2007 \& 2009, GSO. Total: 15 years old or more; authors' calculations.

The structure of secondary jobs also changes significantly. The share of agriculture (in the total of secondary jobs) increased 4.1 points (from $76.4 \%$ to $80.5 \%$ ), mainly at the expense of informal sector jobs (from $18.3 \%$ in 2007 to $15.2 \%$ in 2009). This shift means that, even if we do not observe any noticeable return migration flows to rural areas, an important part of the labour force reinvests agricultural activities to compensate for the hardships on the labour market.

A closer look at the evolution of multi-activity by institutional sectors reveals interesting and counterintuitive patterns, aggregate data being quite misleading. More than ever, multiactivity remains an agricultural phenomenon. The natural hypothesis, quoted in various studies, posits that many non-agriculture workers took advantage of their longstanding connexions with the rural world to complement their income by implementing new agricultural activities. Empirical evidence suggests that it is not the case. For all non agriculture sectors (in the main job), the share of agriculture secondary jobs decreased over the two years, mainly at the benefit of informal sector secondary jobs (and secondarily in favour of other formal jobs). Conversely, the share of secondary agriculture jobs increased for those who were also engaged in agriculture in their main job. These opposite dynamics imply that a diverging process is at stake: the non agricultural labour force is less and less embedded in agricultural activities, while on the contrary the agricultural labour force reduced its attachment to non-agricultural activities, inverting the on-going trend of diversification out of agriculture. The two universes of urban and rural employment seem to be increasingly disconnected.

Table 11: Multi-activity rate by institutional sector, 2007 \& 2009

\begin{tabular}{lcccccc}
\hline & \multicolumn{3}{c}{ Multi-activity rate } & \multicolumn{2}{c}{ Second job sector in 2009 } \\
\cline { 2 - 7 } Public & $\mathbf{2 0 0 7}$ & $\mathbf{2 0 0 9}$ & Change & Formal & Informal & Agriculture \\
\cline { 2 - 7 } Foreign Enterprise & 9.9 & 15.2 & $+5.3 \mathrm{pts}$ & $+1.4 \mathrm{pts}$ & $+6.5 \mathrm{pts}$ & $-7.9 \mathrm{pts}$ \\
Domestic Enterprise & 1.7 & 4.8 & $+3.1 \mathrm{pts}$ & $-3.1 \mathrm{pts}$ & $-1.8 \mathrm{pts}$ & $+4.9 \mathrm{pts}$ \\
Formal HB & 4.6 & 6.8 & $+2.2 \mathrm{pts}$ & $+4.2 \mathrm{pts}$ & $+5.4 \mathrm{pts}$ & $-9.6 \mathrm{pts}$ \\
Informal sector & 6.4 & 11.8 & $+5.4 \mathrm{pts}$ & $+6.6 \mathrm{pts}$ & $+7.8 \mathrm{pts}$ & $-14.4 \mathrm{pts}$ \\
Agriculture & 17.7 & 21.2 & $+3.5 \mathrm{pts}$ & $+0.7 \mathrm{pts}$ & $+3.6 \mathrm{pts}$ & $-4.3 \mathrm{pts}$ \\
\hline Total & 24.4 & 35.9 & $+11.6 \mathrm{pts}$ & $-2.8 \mathrm{pts}$ & $-7.0 \mathrm{pts}$ & $+9.8 \mathrm{pts}$ \\
\hline Sourcs & 18.2 & 25.4 & $+7.2 \mathrm{pts}$ & $-1.0 \mathrm{pts}$ & $-3.1 \mathrm{pts}$ & $+4.1 \mathrm{pts}$ \\
\hline
\end{tabular}

Sources: LFS, 2007 \& 2009, GSO. Total: Occupied population; authors' calculation.

Note: For those engaged in secondary activity and whose main job was in the public sector in 2007, the share of agriculture decreased by -7.9 percentage points between 2007 and 2009 . By construction, the sum of points changes of "formal", "informal" and "agriculture" is 0 . 


\section{Conclusion}

To conclude, some important lessons can be drawn for this analysis. First, concerning the statistical properties of the labour force survey:

* The transfer of the LFS from the MoLISA to the GSO since 2007 has been successful. The quality of the survey improved, both in terms of contents and measurement of the estimators provided (sample design, precision, etc.);

However, there is still some room to proceed further. The changes in the questionnaire through the different rounds of survey (2007-2010) limit the scope of sound and robust comparisons over time. The core questionnaire of the LFS should be stabilized, taking advantage of the experience gained in the recent years. Definitively, unemployment should not be the central indicator of labour market tensions: as unanimously acknowledged, underemployment, informal economy and job's quality are much more meaningful measures in this respect. Capturing informal sector jobs is of key relevance as it is the only way to get a representative sample of IHBs to be surveyed in a second stage (HB\&IS survey). Given its massive importance, secondary job should be systematically investigated. Precise instructions should be given to capture with better precision job status categories;

The periodicity of the LFS should be infra annual. One shot yearly surveys are not appropriate to monitor on time labour market dynamics, shocks and policy response. The two rounds of LFS implemented in 2010 (April and October) is a good first step in this direction. In accordance with previous recommendations and the best international practices, we advocate for a quarterly survey, if possible on a continuous basis over time;

Concerning the analytical part, the empirical evidence suggests that the Vietnamese labour market reacted remarkably well during the crisis. The main features observed are at odds with the expectations (stubbornly low unemployment, resilience of job structure and past trends, strong increase in labour income, etc.), confirming the urgent need of hard data to assess the situation. A few points are worth stressing:

* These unexpected figures may be explained by the formidable (and understated) flexibility of the labor market in Vietnam (both in the formal and informal sector), which allows it to mitigate the negative impact of the global crisis. While the main structures of the labor market remained unaffected overall, the principal variable of adjustment during the slowdown has been the working hours and the multi-activity;

Unfortunately, we will never be able to evaluate the real impact on employment of the crisis, when it hit Vietnam the hardest (that is during 2008 and up to the first quarter of 2009), as no appropriate surveys were conducted during this period. This point reinforce the necessity to design a higher frequency survey scheme;

Lastly, we stressed the impressive labour flexibility, even in the formal sector, which pays a great role for Vietnam to absorb the shocks at the macro level. However, at the individual level, the affected workers and households have fully endured the negative impact of the crisis. More structurally, informal sectors jobs and informal employment remain a massive component of the labour force in Vietnam (24\% and $80 \%$ 
respectively), characterised by poor labour conditions. They will not disappear overnight. Designing targeted policies which combine flexibility and protection remains a key challenge. In particular, the voluntary social insurance scheme, with only 50,000 workers covered by 2009 , should be evaluated.

Compared to 2007, when the first surveys were conducted on behalf of the GSO-IRD project, the informal economy is not a huge black hole any more in Vietnam. Reliable and comprehensive data are now available, and time series began to be available to monitor this key component of the national economy. These results raised awareness of policy makers, at least from a labour market perspective, the informal economy being one important issue considered in the new Viet Nam Employment Strategy 2011-2020 under discussion (MoLISA, 2010). It is now time to proceed further by designing operational policies to be implemented and evaluated.

\section{References}

Cling J.-P., Nguyễn Thị Thu Huyền, Nguyễn Hữu Chí, Phan T. Ngọc Trâm, Razafindrakoto M. \& Roubaud F. (2010a), The Informal Sector in Vietnam: A focus on Hanoi and Ho Chi Minh City, Hanoi: The Gioi Editions.

Cling J.-P., Nguyễn Hữu Chí, Razafindrakoto M. \& Roubaud F. (2010b), How deep was the impact of the economic crisis in Vietnam? A focus on the informal sector in Hanoi and Ho Chi Minh City, Policy Brief, Hanoi: GSO-IRD.

Cling J.-P., Razafindrakoto M. \& Roubaud F. (2010c), "Assessing the Potential Impact of the Global Crisis on the Labour Market and the Informal Sector in Vietnam", Journal of Economics \& Development, 38, June, 16-25.

Demenet A., Nguyễn Thị Thu Huyền, Razafindrakoto M. \& Roubaud F. (2010), Dynamics of the informal sector in Hanoi and Ho Chi Minh City 2007-2009, Hanoi: GSO-IRD.

Dinh Thi Thu Phuong (2009), Rapid assessment on the social impacts of economic crisis in Viet Nam: Case studies on day labourers in "mobile labour markets" in Ha Noi, Hanoi: CAFVASS/Oxfam/World Bank.

GSO (2010), Report on Labour Force and Employment survey. Vietnam 1/9/2009, Hanoi: Ministry of Planning and Investment.

GSO (2008), Report on Labour Force and Employment survey. Vietnam 2007, Ministry of Planning and Investment, Hanoi.

Horn Z.E. (2010), "The effect of the global economic crisis on women in the informal economy: research findings from WIEGO and Inclusive Cities partners", Gender \& Development, 18(2), 263 276.

ILO (2003), “Guidelines Concerning a Statistical Definition of Informal Employment”, Seventeenth International Conference of Labour Statisticians, Geneva: ILO.

ILO \& IMF (2010), The challenges of Growth, Employment and Social Cohesion, Discussion document, Geneva \& Washington D.C.

IPSARD (2009), "Impact of economic slowdown on labourers, employment and life of rural people", Reference Report No.1, Hanoi, May. 
Khanna G., Newhouse D. \& Pacci P. (2010), "Fewer Jobs or Smaller Paychecks? labor market Impacts of the Recent Crisis in Middle-Income Countries", Economic Premise No.11, Washington D.C.: The World Bank.

Le Dang Doanh (2009), Analysis of the Impacts of the Global Financial Crisis on Social and Economic Indicators in Vietnam, Report for UNDP, Hanoi.

MoLISA (2010), Viet Nam Employment Strategy 2011-2020, First Draft, Hanoi, December.

Ngoc Q. Pham (2009), Impact of the Global Financial and Economic Crisis on Viet Nam, paper prepared for the ILO's rapid Assessment Study on the impact of the financial and economic crisis, February.

Nguyễn Ngoc Anh (2009), Rapid assessment on the social impacts of economic crisis in Viet Nam: Case studies on formal sector: enterprises and workers in industrial parks, Hanoi: CAFVASS/Oxfam/World Bank.

Nguyễn Tam Giang (2009), A rapid assessment on the social impacts of the economic crisis on two craft villages, processed, Hanoi: CAF-VASS/Oxfam/World Bank.

Nguyễn Việt Cường, Phạm Thái Hưng \& Phùng Đức Tùng (2009), "Evaluating the Impacts of the Current Economic Slowdown on (Un)employment in Vietnam", Hanoi: UNDP.

Razafindrakoto M. \& Roubaud F. (2007), "Towards a Better Monitoring of the Labor Market", in World Bank, Vietnam Development Report 2008: Social Protection, Joint Donor Report to the Vietnam Consulting Group Meeting, Hanoi, Vietnam.

Riedel J. (2009), “The Global Economic Crisis and Its Long-run Implications for Vietnam”, Hanoi: UNDP, September.

Roubaud F., Dang Kim Chung \& Phan T. Ngọc Trâm (2008), "The Labour Force Surveys (LFS) in Vietnam: Assessment of the past experience and proposals for a new survey design", Hanoi: GSO / UNDP, December.

Razafindrakoto M., Roubaud F. \& Lê Văn Dụy (2008), "Measuring the Informal Sector in Viet Nam: Situation and Prospects", Statistical Scientific Information $\mathrm{N}^{\circ} \mathrm{CS}-02$, Special Issue on Informal Sector, Hanoi, May.

Turk C. \& Mason A. (2010), "Impacts of the economic crisis in East Asia: Findings from qualitative monitoring in five countries" in A. Bauer \& M. Thant, Poverty and Sustainable Development in Asia; Impacts and Responses to the Global Crisis, Manila: Asian Development Bank.

Vietnam Academy of Social Sciences (2009), Rapid Assessment of the Social Impacts of Global Economic Crisis in Viet Nam. Summary of first round research, Oxfam Discussion Paper, Hanoi: CAF-VASS/Oxfam/World Bank, March.

Vietnam Academy of Social Sciences (2010), Poverty Reduction in Vietnam: Achievements and Challenges, Vietnam's Poverty Assessment 2008-2010: Synthesis report, Hanoi.

Warren-Rodríguez A. (2009), "The impact of the global crisis downturn on employment levels in Viet Nam: an elasticity approach", UNDP Viet Nam Technical Note, February.

World Bank (2009), Taking Stock: An Update on Vietnam's, Recent Economic Developments, Hanoi: The World Bank, June. 